\title{
Preventive Service Gains from First Contact Access in the Primary Care Home
}

\author{
Nancy Pandhi, MD, MPH, Jennifer E. DeVoe, MD, DPhil, Jessica R. Schumacher, PhD, \\ Christie Bartels, MD, MS, Carolyn T. Thorpe, PhD, MPH, \\ Joshua M. Thorpe, PhD, MPH, and Maureen A. Smith, MD, PhD, MPH
}

Background: The patient-centered medical home (РСMH) concept recently has garnered national attention as a means of improving the quality of primary care. Preventive services are one area in which the use of a PCMH is hoped to achieve gains, though there has been limited exploration of PCMH characteristics that can assist with practice redesign. The purpose of this study was to examine whether firstcontact access characteristics of a medical home (eg, availability of appointments or advice by telephone) confer additional benefit in the receipt of preventive services for individuals who already have a longitudinal relationship with a primary care physician at a site of care.

Methods: This was a secondary analysis examining data from 5507 insured adults with a usual physician who participated in the 2003 to 2006 round of the Wisconsin Longitudinal Study. Using logistic regression, we calculated the odds of receiving each preventive service, comparing individuals who had first-contact access with those without first-contact access.

Results: Eighteen percent of the sample received care with first-contact access. In multivariable analyses, after adjustment, individuals who had first-contact access had higher odds of having received a prostate examination (odds ratio [OR], 1.62; 95\% CI, 1.20-2.18), a flu shot (OR, 1.36; 95\% CI, 1.011.82), and a cholesterol test $(\mathrm{OR}, 1.36 ; 95 \% \mathrm{CI}, 1.01-1.82)$ during the past year. There was no significant difference in receipt of mammograms (OR, 1.23; 95\% CI, 0.94-1.61).

Conclusions: In the primary care home, first-contact accessibility adds benefit, beyond continuity of care with a physician, in improving receipt of preventive services. Amid increasing primary care demands and finite resources available to translate the PCMH into clinic settings, there is a need for further studies of the interplay between specific PCMH principles and how they perform in practice. (J Am Board Fam Med 2011;24:351-359.)

Keywords: Access to Care, Continuity of Care, Patient-Centered Medical Home, Preventive Medicine, Quality Improvement

The patient-centered medical home (PCMH) concept has garnered national attention as a means of improving the quality of primary care ${ }^{1-4}$ although its definition is continually evolving. ${ }^{5,6}$ Preventive

This article was externally peer reviewed.

Submitted 27 October 2010; revised 2 March 2011; accepted 7 March 2011.

From the Departments of Family Medicine and Population Health Sciences (NP, MAS), University of Wisconsin, Madison; the Department of Family Medicine, Oregon Health \& Science University, Portland (JED); Department of Health Services Research, Management and Policy, University of Florida, Gainesville (JRS); the Department of Medicine, Rheumatology Section (CB), the Health Innovation Program, Department of Population Health Sciences (CTT, MAS), and the Department of Surgery (MAS), University of Wisconsin School of Medicine and Public Health, services are one area in which the PCMH is hoped to achieve gains. ${ }^{7}$ In the context of modern primary care demands and limited primary care resources, providing optimal preventive care to all patients is

Madison; the Division of Social and Administrative Sciences and the Sonderegger Research Center, University of Wisconsin-Madison School of Pharmacy, Madison (JMT).

Funding: This project was supported by the Health Innovation Program and the Community-Academic Partnerships core of the University of Wisconsin Institute for Clinical and Translational Research funded through an National Institutes of Health Clinical and Translational Science Award, grant no. 1 UL1 RR025011. In addition, NP is supported by a National Institute on Aging Mentored Clinical Scientist Research Career Development Award, grant number 1 K08 AG029527. JED's time on this project was supported by grant no. K08 HS16181 from the Agency 
extremely difficult. ${ }^{8,9}$ It has been estimated that 7.4 hours each day would be required for primary care physicians to deliver all guideline-recommended preventive care. ${ }^{10}$ Despite enormous investment, efforts to date that aim to improve the delivery of preventive services have not shown sustained improvement. ${ }^{8,11,12}$ However, increasing the rate of delivery of preventive services has significant potential to improve mortality, ${ }^{13,14}$ and the one study published to date found that patients with primary care delivered according to PCMH principles had increased receipt of preventive services. ${ }^{15}$

Though numerous demonstrations currently are underway to examine the medical home's efficacy, ${ }^{16}$ practices striving for PCMH status are faced with investing in the difficult task of redesigning the care they provide without a clear sense of expected return. The PCMH concept centers around executing several key primary care functions, but it is unclear which medical home characteristics should be given priority in practice redesign because requirements for PCMH status vary by region and by payer. For example, continuity with a personal provider is a required criterion only in the Center for Medicaid Services' version of the National Center for Quality Assurance medical home guidelines, ${ }^{17}$ but not other (National Center for Quality Assurance) guidelines. ${ }^{7}$ Therefore, there is need for further research to determine what specific aspects of the PCMH provide benefit and in what areas they have the potential to do so.

for Healthcare Research and Quality. This project was also supported by the University of Wisconsin Carbone Cancer Center Support Grant from the National Cancer Institute, grant no. P30 CA014520. Additional support was provided by the University of Wisconsin School of Medicine and Public Health from the Wisconsin Partnership Program.

Conflict of interest: none declared.

Disclaimer: This research uses data from the Wisconsin Longitudinal Study of the University of Wisconsin-Madison. Since 1991, the Wisconsin Longitudinal Study has been supported principally by the National Institute on Aging (R01 AG09775, R01 AG033285), with additional support from the Vilas Estate Trust, the National Science Foundation, the Spencer Foundation, and the Graduate School of the University of Wisconsin-Madison. A public use file of data from the Wisconsin Longitudinal Study is available from the Wisconsin Longitudinal Study, University of Wisconsin-Madison, 1180 Observatory Drive, Madison, Wisconsin, 53706 and at http://www.ssc.wisc.edu/wlsresearch/ data/.

Corresponding author: Nancy Pandhi, MD, MPH, Department of Family Medicine, University of Wisconsin, 800 University Bay Drive, Box 9445, Madison, WI 53705 (E-mail: nancy.pandhi@fammed.wisc.edu).
Although 2 characteristics of the PCMH-firstcontact access, ${ }^{17,18}$ defined as the availability and accessibility of services, ${ }^{15} \mathrm{eg}$, availability of appointments or advice by telephone, and continuity of care with a physician ${ }^{19-22}$ - have each been associated independently with improved receipt of preventive care, little is known about the impact of first-contact access on receipt of preventive services among patients with a high degree of continuity of care. Previous studies also have focused more on general access characteristics such as insurance status and having a usual source of care ${ }^{23-27}$ rather than characteristics more specific to first-contact access at a particular clinic, such as the availability of appointments or advice by telephone. In addition, these studies tend not to measure health care access as it is perceived by patients, although this perception is important for developing an understanding of the patient-centered portion of the PCMH. Though measures such as insurance and appointment availability are markers of a patient's potential to access care, perceptions of access also are known to influence the location and pattern of health care service use. ${ }^{18,28-31}$ The only study that has examined the association between PCMH characteristics (including first-contact care and continuity) and preventive care investigated only 2 characteristics of perceived access in a practice, recruited patients as they were accessing care in a primary care clinic, and did not examine the receipt of individual preventive services. ${ }^{15}$ Examining these services individually and in a community-based sample is important given that access factors may vary according to the type of preventive service. For example, the access factors influencing the receipt of mammograms, which patients often schedule directly, may be very different from factors influencing receipt of a cholesterol test, which physicians must order. ${ }^{32}$

This study was designed to increase our understanding of whether the PCMH characteristic of first-contact access has a positive influence on the receipt of individual preventive services above and beyond the impact of having a high degree of continuity with a physician. To examine this question, we focused our analysis on a sample of insured older adults who reported at least 2 years of continuity with a primary care physician. Specifically, we examined the additional effect of first-contact access on the receipt of 4 preventive health measures: cholesterol screening, influenza vaccination, mam- 
mograms, and prostate screening. We expected that the receipt of cholesterol screening, influenza vaccination, and prostate screening would be additionally increased by first-contact access because they are preventive services received in a primary care office. Conversely, we expect to see no effect of first-contact access on mammograms, which are generally scheduled in other locations.

\section{Methods \\ Sample}

The sample was defined within the Wisconsin Longitudinal Study, a cohort study of a one-third random sample $(\mathrm{n}=10,317)$ of individuals who graduated from Wisconsin high schools in the spring of 1957 and 8,778 of their randomly selected siblings. Data were from the 2003 to 2006 rounds of the combined telephone and mail survey. Among graduate survivors, the response rate for this survey was $80 \%$, and for siblings the response rate was $78 \%$. To include only those respondents who had evidence of an established continuity of care relationship with an individual primary care physician, the sample was further restricted. We excluded respondents who reported no visits to a health professional during the past 12 months $(7 \%)$ or who were uninsured (3\%). We included respondents who reported usually seeing, for at least 2 years, the same health professional (a general/family practice or internal medicine physician) when they went to their usual medical facility. The final sample size was 5507 , consisting of $69 \%$ of the sample who responded to the survey in 2004 to 2006. This study was approved by the institutional review board at the participating university.

\section{Variables/Measures}

The primary dependent variables were patient report of preventive services during the last year as assessed by response to yes/no questions that asked, During the last 12 months, have you had (1) a cholesterol test; (2) a flu shot; (3) a mammogram (women); and/or (4) a prostate examination (men)? Self-report of the preventive services studied generally has been found to have high sensitivity and lower specificity when compared with the medical record. ${ }^{33,34}$ Guidelines in place at the time of the study ${ }^{35-38}$ were used to determine the appropriate sample for receipt of each preventive service. Specifically, we looked at the receipt of cholesterol testing among those with atherosclerotic vascular disease conditions (high blood pressure, coronary heart disease/myocardial infarction, circulation problems, stroke, high cholesterol) and diabetes. We examined the receipt of influenza vaccination among those aged 50 or older. We limited the sample for mammogram screening to women aged 40 or older and prostate screening to men aged 50 or older.

First-contact accessibility was assessed using 8 items from the validated access to care subscale of the Group Health Association of America Consumer Satisfaction Survey, ${ }^{39}$ as shown in Table 1. These items were chosen based on their similarity to items used in prior medical home literature. ${ }^{40}$ Response categories were excellent, very good, good, fair, or poor. Those answering very good or excellent to all 8 questions were considered to have highly rated first-contact accessibility. Covariates included in all models were age, sex, marital status, education, total household income, type of health insurance, self-rated health, and a count of chronic conditions.

\section{Statistical Analysis}

Data were analyzed in 2010 using Stata software (version 11.0, StataCorp, LP, College Station, TX). Initial analysis included comparison of variable means and percentages between respondents with and without very good to excellent first-contact accessibility using analysis of variance and $\chi^{2}$ tests. Differences were considered statistically significant

\section{Table 1. Items from the 2004 to 2006 Wisconsin Longitudinal Study Used to Define Desirable First- Contact Accessibility}

Thinking about your own health care, how would you rate*:

The convenience of location of the doctor's office?

The hours when the doctor's office is open?

Arrangements for making appointments for medical care by phone?

The length of time spent waiting at the office to see the doctor?

The length of time you wait between making an appointment for routine care and the day of your visit?

The availability of medical information or advice by phone?

The ease of seeing the doctor of your choice?

The amount of time you have with doctors and staff during a visit?

* Responses on a scale of 1 to 5 (poor, fair, good, very good, excellent); a 4 or 5 on all items is needed to qualify. 
at a value of $P<.05$. Using multivariable logistic regression, adjusted odds ratios (ORs) and $95 \%$ CIs were calculated for each preventive service. After estimation, adjusted average predicted probabilities were calculated. Confidence intervals were calculated using a robust estimate of the variance that allowed for clustering of siblings within families. We also performed a subanalysis comparing unadjusted and adjusted odds ratios and 95\% CIs for each preventive service for patients seen by family practice/general practice physicians $(n=3632)$ and internal medicine physicians $(\mathrm{n}=1875)$ to assess the differential effect first-contact access may have on preventive care receipt by physician specialty.

\section{Results}

Eighteen percent of the sample reported highly rated first-contact accessibility to their primary care clinic in addition to continuity of care with their primary care physician (Table 2). These individuals were older, more likely to be women, and had a slightly lower mean number of chronic conditions and slightly higher self-rated health.

During the past 12 months, $83 \%$ of those eligible had received a mammogram, $78 \%$ had received a prostate examination, $90 \%$ had received a cholesterol test, and $63 \%$ had received an influenza vaccination. In both unadjusted and adjusted analyses, individuals in this insured cohort who had a continuity of care relationship with a primary care physician and who reported highly rated first-contact accessibility had higher odds of having received a prostate examination (adjusted OR, 1.62; 95\% CI, $1.20-2.18$ ) and a flu shot (adjusted OR,1.36; 95\% CI, 1.16-1.59) during the past year (Table 3), compared with those who had a continuity relationship alone. The percentage of patients receiving a prostate examination increased from $76 \%$ to $84 \%$, and receipt of a flu shot increased from $61 \%$ to $68 \%$. In adjusted analyses only, individuals who reported highly rated first-contact accessibility had higher odds of having received a cholesterol test (adjusted OR, 1.36; 95\% CI, 1.01-1.82). This percentage increased from $90 \%$ to $92 \%$. There was no significant difference in receipt of mammograms (OR, 1.23 ; 95\% CI, 0.94-1.61). There was no significant difference in the odds of receiving preventive services between patients seen by family practice/general practice physicians and internal medicine physicians.

\section{Discussion}

Our findings lend support to the national movement that is encouraging primary care practice redesign into $\mathrm{PCMHs}$ and highlights first contact access as a characteristic that predicts increases in most preventive services. In our study, the addition of first contact access for patients who already had continuity of care with a primary care physician was associated with higher receipt of preventive services when compared with having continuity of care alone. Specifically, we found that patients who reported highly rated first-contact access to care had improved receipt of prostate examinations, flu shots, and cholesterol tests compared with those who had continuity of care with a primary care physician alone. Rates of receipt of mammograms were not significantly different among those with highly rated first contact access versus those without this additional PCMH characteristic.

Our study population, which consisted of $69 \%$ of the surviving original cohort who responded to the survey in 2003 to 2006, had relatively high rates of preventive service use compared with the national population at the time of the study. For example, during the prior 12 months, $83 \%$ of our sample had received a mammogram compared with $77 \%$ nationally ${ }^{41} ; 78 \%$ had received a prostate examination compared with $50 \%$ nationally ${ }^{42} ; 90 \%$ had received a cholesterol test compared with $85 \%$ to $88 \%$ nationally ${ }^{43}$; and $63 \%$ had received an influenza vaccination compared with $50 \%$ nationally. ${ }^{44}$ Even in this relatively well-educated population with excellent continuity of care and high receipt of preventive services, the addition of firstcontact accessibility increased the odds of individuals receiving flu shots, prostate examinations, and cholesterol screening. Although the increase in odds of receipt of preventive services was small in some cases, when translated to national health indicators, these small increases have potentially large payoffs.

Our findings also have implications for the ongoing discussion regarding the relationship between continuity of care with a personal physician and access to care. ${ }^{45-48}$ Continuity of care is difficult to achieve in open access models with parttime providers. ${ }^{49,50}$ There has been a shift away from personal continuity ${ }^{51,52}$ and an increase in primary care providers that practice part time, though this may be offset by other strategies. ${ }^{53}$ Our 


\begin{tabular}{|c|c|c|c|c|}
\hline & \multirow[b]{2}{*}{ Overall Population } & \multicolumn{3}{|c|}{ By First-Contact Accessibility Status } \\
\hline & & $\begin{array}{l}\text { With First-Contact } \\
\text { Accessibility }\end{array}$ & $\begin{array}{c}\text { Without First-Contact } \\
\text { Accessibility }\end{array}$ & $P$ \\
\hline First-contact accessibility status & & $967(18)$ & $4540(82)$ & \\
\hline Age (years) & & & & .03 \\
\hline $0-59$ & $496(9)$ & $71(7)$ & $425(9)$ & \\
\hline $60-64$ & $2829(51)$ & $479(50)$ & $2350(52)$ & \\
\hline $65-69$ & $1677(30)$ & $314(32)$ & $1363(30)$ & \\
\hline$\geq 70$ & $505(9)$ & $103(11)$ & $402(9)$ & \\
\hline Sex & & & & .02 \\
\hline Male & $2567(47)$ & $417(43)$ & $2150(47)$ & \\
\hline Female & $2940(53)$ & $550(57)$ & $2390(53)$ & \\
\hline Marital status & & & & .20 \\
\hline Married & $4429(80)$ & $790(82)$ & $3639(80)$ & \\
\hline Separated or divorced & $470(9)$ & $70(7)$ & $400(9)$ & \\
\hline Widowed & $411(7)$ & $79(8)$ & $332(7)$ & \\
\hline Never married & $195(4)$ & $28(3)$ & $167(4)$ & \\
\hline Educational attainment & & & & .36 \\
\hline$\leq$ High school & $2963(54)$ & $534(56)$ & $2429(54)$ & \\
\hline Some college & $854(16)$ & $133(14)$ & $721(16)$ & \\
\hline College & $807(15)$ & $149(16)$ & $658(15)$ & \\
\hline Postgraduate & $831(15)$ & $145(15)$ & $686(15)$ & \\
\hline Total household income (\$) & & & & .13 \\
\hline$<30,000$ & $1015(18)$ & $197(20)$ & $818(18)$ & \\
\hline $30,000-44,999$ & $935(17)$ & $175(18)$ & $760(17)$ & \\
\hline $45,000-59,999$ & $823(15)$ & $155(16)$ & $668(15)$ & \\
\hline $60,000-74,999$ & $715(13)$ & $117(12)$ & $598(13)$ & \\
\hline$>75,000$ & $1781(32)$ & $287(30)$ & $1494(33)$ & \\
\hline Not provided & $238(4)$ & $36(4)$ & $202(4)$ & \\
\hline Health insurance & & & & .06 \\
\hline Private & $3071(56)$ & $503(52)$ & $2568(57)$ & \\
\hline Medicare and other private & $1886(34)$ & $352(36)$ & $1534(34)$ & \\
\hline Medicare or other public & $550(10)$ & $112(12)$ & $438(10)$ & \\
\hline Chronic conditions (mean $\mathrm{n}[\mathrm{SD}])^{\dagger}$ & $4.0(2.5)$ & $3.8(2.4)$ & $4.0(2.5)$ & $<.01$ \\
\hline Self-rated health (mean $[\mathrm{SD}])^{\ddagger}$ & $3.7(1.0)$ & $3.9(1.0)$ & $3.7(0.9)$ & $<.01$ \\
\hline
\end{tabular}

Sample consists of patients who have reported a continuity relationship with a Family Medicine or Internal Medicine Physician of at least 2 years.

All values are presented as $\mathrm{n}(\%)$ unless otherwise indicated.

*First-contact accessibility status is defined as very good or excellent ratings for all of the following: convenience of doctor's location, hours of doctor's availability, phone appointment arrangements, office wait time, time between when appointment is made and visit, availability by phone of medical advice and information, ease of seeing doctor of choice, and amount of visit time spent with doctors and staff. The sample consists of patients who have reported a continuity relationship of at least 2 years with a family medicine or internal medicine physician. Because of rounding, percents may not add up to 100 .

${ }^{\dagger}$ The following 22 chronic conditions were measured in this count: asthma, bronchitis/emphysema, serious back trouble, circulation problems, kidney/bladder problems, ulcers, allergies, multiple sclerosis, high blood pressure, diabetes, cancer, coronary heart disease/myocardial infarction, stroke, arthritis, pain and stiffness in the joints, mental illness, chronic sinusitis, fibromyalgia, high cholesterol, irritable bowel syndrome, osteoporosis, and prostate problems.

${ }^{\ddagger}$ Self-rated health was measured by respondents on a scale of 1 to 5 (poor, fair, good, very good, excellent).

findings imply that provider continuity and access to care jointly benefit receipt of preventive services. This suggests that primary care office models are needed that can balance these 2 areas and also develop advanced systems that can adapt to the changing demographics of the provider work- 
Table 3. Preventive Services Receipt for Those With Continuity of Care, Comparing Those With $(N=967)$ and Without $(\mathrm{N}=4540)$ First-Contact Accessibility

\begin{tabular}{|c|c|c|c|}
\hline & $\mathrm{n} / \mathrm{N}(\%)$ & Unadjusted (OR [95\% CI]) & Adjusted $^{*}(\mathrm{OR}[95 \% \mathrm{CI}])$ \\
\hline \multicolumn{4}{|l|}{ Cholesterol test } \\
\hline With first-contact accessibility & $657 / 714(92)$ & $1.29(0.96-1.73)$ & $1.36(1.01-1.82)$ \\
\hline Without first-contact accessibility & $3053 / 3395(90)$ & 1.00 & 1.00 \\
\hline \multicolumn{4}{|l|}{ Flu shot } \\
\hline With first-contact accessibility & $646 / 948(68)$ & $1.35(1.16-1.57)$ & $1.36(1.16-1.59)$ \\
\hline Without first-contact accessibility & $2731 / 4451(61)$ & 1.00 & 1.00 \\
\hline \multicolumn{4}{|l|}{ Prostate examination } \\
\hline With first-contact accessibility & $327 / 391(84)$ & $1.58(1.19-2.11)$ & $1.62(1.2-2.18)$ \\
\hline Without first-contact accessibility & $1519 / 1990(76)$ & 1.00 & 1.00 \\
\hline \multicolumn{4}{|l|}{ Mammogram } \\
\hline With first-contact accessibility & $464 / 542(86)$ & $1.24(0.96-1.62)$ & $1.23(0.94-1.61)$ \\
\hline Without first-contact accessibility & $1943 / 2349(83)$ & 1.00 & 1.00 \\
\hline
\end{tabular}

This sample consists of patients who have reported a continuity relationship of at least 2 years with a family medicine or internal medicine physician. Bolded values are significant at $P<.05$.

*Adjusted for age, household income, education, marital status, sex, insurance type, chronic conditions count, and self-rated health. OR, odds ratio.

force. In addition, further research is needed to explore how patients perceive first-contact access to their continuity physician with regard to receiving individual preventive services and how this may vary according to different types of preventive services.

Similar to other studies that have examined the associations between receipt of preventive services and continuity of care ${ }^{20,32}$ receiving mammograms did not increase with first-contact access. One explanation is that the effects of first-contact access on preventive services may not extend beyond the point of care. Mammograms are the only service we examined that usually was not completed in the primary care office. Alternatively, the mammography screening rate among our population was quite high. Given that receiving a mammograms is dependent on provider and patient characteristics and the logistics of another imaging site, ${ }^{11,32}$ it may be difficult for primary care clinics to further improve this rate.

Despite strengths of this comprehensive data, these findings should be considered in light of several limitations. This sample represents individuals who attended Wisconsin high schools in the 1950s and therefore is limited in geographical and racial/ethnic diversity. However, Wisconsin Longitudinal Study graduates are generally representative of non-Hispanic white women and men with a high school education, constituting approximately $67 \%$ of Americans aged 60 to
64. ${ }^{54} \mathrm{We}$ also restricted the sample to individuals with insurance and continuity of care to test the additional effect of first-contact access on receipt of preventive services. Therefore, our sample is not generalizable to all patients seen in primary care. Receipt of preventive services was measured using self-report, which has been found to be overestimated when compared with the medical record. ${ }^{55-58}$ However, there is no reason to believe any estimation differences would be different for those with and without desirable firstcontact accessibility. It is possible that individuals who received better preventive care were more likely to perceive access to care more positively. We used clinical preventive service guideline age cutoffs that were in place at the time of data collection, which have changed recently for certain preventive services. In particular, prostate cancer screening is no longer recommended for men over the age of $75,{ }^{59}$ and influenza vaccination is now recommended for those older than the age of 6 months. ${ }^{60}$ Annual prostate examination in the current clinical environment may be considered an example of overutilization. Lastly, influenza vaccination was available in public clinics and drug stores during the years of the study. Therefore, it is difficult to know if individuals received these immunizations in their primary care clinic or elsewhere. However, a principle of the medical home is that such care should be delivered and tracked through the primary care 
system, which will become increasingly important as accountable care organizations track and measure the delivery of high-quality care.

\section{Conclusion}

Our findings suggest that first-contact accessibility adds benefit, beyond continuity of care with a physician, to improve receipt of preventive services in the primary care PCMH. Amid increasing primary care demands and limited primary care resources, studies examining the impact of specific components of the PCMH may help redesign efforts. There is a need for further studies of the interplay between specific $\mathrm{PCMH}$ principles and how they perform in practice.

\section{References}

1. Rittenhouse DR, Shortell SM. The patient-centered medical home: Will it stand the test of health reform? JAMA 2009;301(19):2038-40.

2. Nutting PA, Miller WL, Crabtree BF, Jaen CR, Stewart EE, Stange KC. Initial lessons from the first national demonstration project on practice transformation to a patient-centered medical home. Ann Fam Med 2009;7(3):254-60.

3. Rosenthal TC. The medical home: growing evidence to support a new approach to primary care. J Am Board Fam Med 2008;21(5):427-40.

4. Barr MS. The need to test the patient-centered medical home. JAMA 2008;300(7):834-5.

5. DuBard CA, Stange KC, Nutting PA, et al. Moving forward with the medical home: evidence, expectations, and insights from CCNC. Defining and measuring the patient-centered medical home. N C Med J 2009;70(3):225-30.

6. Stange KC, Nutting PA, Miller WL, et al. Defining and measuring the patient-centered medical home. J Gen Intern Med 2010;25(6):601-12.

7. National Committee for Quality Assurance. Standards and Guidelines for Physician Practice Connections: patient-centered medical home. Washington, DC: National Committee for Quality Assurance; 2008.

8. Yarnall KS, Ostbye T, Krause KM, Pollak KI, Gradison M, Michener JL. Family physicians as team leaders: "time" to share the care. Prev Chronic Dis 2009;6(2):A59.

9. Blendon RJ, Schoen C, DesRoches CM, Osborn R, Zapert K, Raleigh E. Confronting competing demands to improve quality: a five-country hospital survey. Health Aff (Millwood) 2004;23(3): 119-35.

10. Yarnall KS, Pollak KI, Ostbye T, Krause KM, Michener JL. Primary care: is there enough time for prevention? Am J Public Health 2003;93(4): $635-41$.

11. Centers for Disease Control and Prevention. Vital signs: breast cancer screening among women aged 50-74 years - United States, 2008. MMWR Morb Mortal Wkly Rep 2010;59(26):813-6.

12. Melnikow J, Kohatsu ND, Chan BK. Put prevention into practice: a controlled evaluation. Am J Public Health 2000;90(10):1622-5.

13. Farley TA, Dalal MA, Mostashari F, Frieden TR. Deaths preventable in the U.S. by improvements in use of clinical preventive services. Am J Prev Med 2010;38(6):600-9.

14. Maciosek MV, Coffield AB, Edwards NM, Flottemesch TJ, Goodman MJ, Solberg LI. Priorities among effective clinical preventive services: results of a systematic review and analysis. Am J Prev Med 2006;31(1):52-61.

15. Ferrante JM, Balasubramanian BA, Hudson SV, Crabtree BF. Principles of the patient-centered medical home and preventive services delivery. Ann Fam Med 2010;8(2):108-16.

16. Bitton A, Martin C, Landon BE. A nationwide survey of patient centered medical home demonstration projects. J Gen Intern Med 2010;25(6):584-92.

17. Bindman AB, Grumbach K, Osmond D, Vranizan K, Stewart AL. Primary care and receipt of preventive services. J Gen Intern Med 1996;11(5):269-76.

18. Okoro CA, Strine TW, Young SL, Balluz LS, Mokdad AH. Access to health care among older adults and receipt of preventive services. Results from the Behavioral Risk Factor Surveillance System, 2002. Prev Med 2005;40(3):337-43.

19. Blewett LA, Johnson PJ, Lee B, Scal PB. When a usual source of care and usual provider matter: adult prevention and screening services. J Gen Intern Med 2008;23(9):1354-60.

20. Fenton JJ, Franks P, Reid RJ, Elmore JG, Baldwin LM. Continuity of care and cancer screening among health plan enrollees. Med Care 2008;46(1):58-62.

21. Doescher MP, Saver BG, Fiscella K, Franks P. Preventive care. J Gen Intern Med 2004;19(6):632-7.

22. Saultz JW, Lochner J. Interpersonal continuity of care and care outcomes: a critical review. Ann Fam Med 2005;3(2):159-66.

23. Corbie-Smith G, Flagg EW, Doyle JP, O'Brien MA. Influence of usual source of care on differences by race/ethnicity in receipt of preventive services. J Gen Intern Med 2002;17(6):458-64.

24. Breen N, Wagener DK, Brown ML, Davis WW, Ballard-Barbash R. Progress in cancer screening over a decade: results of cancer screening from the 1987, 1992, and 1998 National Health Interview Surveys. J Natl Cancer Inst 2001;93(22):1704-13.

25. Hsia J, Kemper E, Kiefe C, et al. The importance of health insurance as a determinant of cancer screening: evidence from the Women's Health Initiative. Prev Med 2000;31(3):261-70. 
26. Selvin E, Brett KM. Breast and cervical cancer screening: sociodemographic predictors among white, black, and Hispanic women. Am J Public Health 2003;93(4): 618-23.

27. DeVoe JE, Fryer GE, Phillips R, Green L. Receipt of preventive care among adults: insurance status and usual source of care. Am J Public Health 2003;93(5): 786-91.

28. Shavers VL, Shankar S, Alberg AJ. Perceived access to health care and its influence on the prevalence of behavioral risks among urban African Americans. J Natl Med Assoc 2002;94(11):952-62.

29. Kontopantelis E, Roland M, Reeves D. Patient experience of access to primary care: identification of predictors in a national patient survey. BMC Fam Pract 2010;11:61.

30. Rust G, Ye J, Baltrus P, Daniels E, Adesunloye B, Fryer GE. Practical barriers to timely primary care access: impact on adult use of emergency department services. Arch Intern Med 2008;168(15):1705-10.

31. Ragin DF, Hwang U, Cydulka RK, et al. Reasons for using the emergency department: results of the EMPATH Study. Acad Emerg Med 2005;12(12): $1158-66$.

32. Xu KT. Usual source of care in preventive service use: a regular doctor versus a regular site. Health Serv Res 2002;37(6):1509-29.

33. Martin LM, Leff M, Calonge N, Garrett C, Nelson DE. Validation of self-reported chronic conditions and health services in a managed care population. Am J Prev Med 2000;18(3):215-8.

34. Hall HI, Van Den Eeden SK, Tolsma DD, et al. Testing for prostate and colorectal cancer: comparison of self-report and medical record audit. Prev Med 2004;39(1):27-35.

35. American Cancer Society. American Cancer Society guidelines for the early detection of cancer. 5 March 2008. Available at: http://www.cancer.org/docroot/ PED/content/PED_2_3X_ACS_Cancer_Detection_ Guidelines_36.asp. Accessed 12 March 2008.

36. National Cholesterol Education Program. Detection, evaluation and treatment of high blood cholesterol in adults (Adult Treatment Panel III). Bethesda: National Institutes of Health, National Heart, Lung, and Blood Institute; 2002.

37. Bridges CB, Harper SA, Fukuda K, Uyeki TM, Cox NJ, Singleton JA. Prevention and control of influenza. Recommendations of the Advisory Committee on Immunization Practices (ACIP). MMWR Recomm Rep 2003;52(RR-8):1-36.

38. Agency for Healthcare Research and Quality. The pocket guide to clinical preventive services 2005 . Rockville, MD: Agency for Healthcare Research and Quality; 2005.

39. Davies AR, Ware JE. GHAA's consumer satisfaction survey and user's manual, 2nd ed. Washington, DC: Group Health Association of America; 1991.
40. Beal AC, Doty MM, Hernandez MM, Shea KK, Davis K. Closing the divide: how medical homes promote equity in health care-results from The Commonwealth Fund 2006 Health Care Quality Survey. Washington, DC; 2007.

41. Centers for Disease Control and Prevention. Behavioral Risk Factor Surveillance System survey data. Atlanta: Centers for Disease Control and Prevention; 2006.

42. Brown E Jr. Screening for prostate cancer with the prostate-specific antigen test - United States, 2006. Statistical Brief \#233. Rockville, MD: Agency for Healthcare Research and Quality; 2009.

43. Wilson AR, Rodin H, Garrett NA, et al. Comparing quality of care between a consumer-directed health plan and a traditional plan: an analysis of HEDIS measures related to management of chronic diseases. Popul Health Manag 2009;12(2):61-7.

44. National Center for Health Statistics. Data file documentation, National Health Interview Survey, 2004 (machine readable data file and documentation). Hyattsville, MD: National Center for Health Statistics, Centers for Disease Control and Prevention; 2005.

45. Haggerty J. The future for personal doctoring. Br J Gen Pract 2009;59(561):236-7.

46. Salisbury C, Montgomery AA, Simons L, et al. Impact of Advanced Access on access, workload, and continuity: controlled before-and-after and simulated-patient study. Br J Gen Pract 2007; 57(541):608-14.

47. Mainous AG 3rd, Salisbury C. Advanced access, open access, and continuity of care: should we enforce continuity? Fam Med 2009;41(1):57-8.

48. Starfield B. Primary care: balancing health needs, services, and technology. New York: Oxford University Press; 1998.

49. Murray M, Bodenheimer T, Rittenhouse D, Grumbach K. Improving timely access to primary care: case studies of the advanced access model. JAMA 2003;289(8):1042-6.

50. Pham HH, Schrag D, Hargraves JL, Bach PB. Delivery of preventive services to older adults by primary care physicians. JAMA 2005;294(4):47381.

51. Hjortdahl P. Continuity of care-going out of style? Br J Gen Pract 2001;51(470):699-700.

52. Manian FA. Whither continuity of care? N Engl J Med 1999;340(17):1362-3.

53. American Medical Group Association. 2007 physician retention survey. Available at: https://ecommerce.amga.org/ iMISPublic/Core/Orders/category.aspx?catid=193. Accessed 6/6/2011.

54. U.S. Bureau of the Census. Educational attainment in the United States: March 2000. Washington, DC: Government Printing Office; 2000.

55. Fiscella K, Holt K, Meldrum S, Franks P. Disparities in preventive procedures: comparisons of self-report 
and Medicare claims data. BMC Health Serv Res 2006;6:122.

56. Mac Donald R, Baken L, Nelson A, Nichol KL. Validation of self-report of influenza and pneumococcal vaccination status in elderly outpatients. Am J Prev Med 1999;16(3):173-7.

57. May DS, Trontell AE. Mammography use by elderly women: a methodological comparison of two national data sources. Ann Epidemiol 1998;8(7): 439-44.

58. Hiatt RA, Perez-Stable EJ, Quesenberry C Jr, Sabogal F, Otero-Sabogal R, McPhee SJ. Agreement be- tween self-reported early cancer detection practices and medical audits among Hispanic and non-Hispanic white health plan members in northern California. Prev Med 1995;24(3):278-85.

59. U.S. Preventive Services Task Force. The guide to clinical preventive services 2010-2011. Rockville, MD: Agency for Healthcare Reseach and Quality; 2010.

60. Advisory Committee on Immunization Practices. Recommended adult immunization schedule: United States, 2010. Ann Intern Med 2010;152(1): 36-9. 